quite in harmony with the multiple origin of the historic and recent races of horses as recently established by Profs. Ridgeway and Ewart. The Pliocene horse of America still requires further exploration before it can be positively affirmed either that all the links to Equus are complete or that America is indubitably the source of this genus. The Lower Pleistocene of America exhibits a great variety of races, ranging in size from horses far more diminutive than the smallest Shetland to those exceeding the largest modern draught breeds-yet all these races became extinct, and did not survive into the human period as was the case in South America. The relations of these North American races to those of South America and of Asia and Africa is a subject requiring further investigation.

The address was illustrated by photographs of a large series of models, of osteological preparations showing the mechanism and breeds of the horse, and of the mounted fossil specimens recently discovered.

Prof. Ewart referred to the fact that in pre-Glacial times there were several distinct species of Equidæ in the New World, and that one of the objects of present inquiry is to connect the recent Equidæ with these or other extinct forms. Before it is possible to point out the connection between the true horses and the pre-Glacial or Pleistocene horses it is necessary to determine the number of species and varieties of the horse now extant. He described at some length Prjevalsky's horse, the Norse type of horse still found fairly pure in the north-west of Scotland, and the recently discovered Celtic pony. He referred to Prjevalsky's horse as the least specialised of living Equidæ, as evidenced by the character of its mane and tail and the presence of a complete set of callosities, and he discussed the question as to whether it is a mule or simply the offspring of Mongolian ponies run wild. The Norse type of horse differs from Prjevalsky's in its heavy mane and tail, finer head, and smaller ears. The Celtic pony is the most specialised of living Equidæ, as shown by the absence of such vestiges as fetlock-pads and chestnuts from the hind legs, and the presence of a peculiar tail-lock which adapts it for a subarctic habitat. Photographs were shown to illustrate these various features.

Prof. Ridgeway then stated some of the evidence which led him to conclude that a distinct species or variety of the horse had been specialised in North Africa. Darwin supposed that not only was the Arab horse the result of artificial breeding by the Arabs, but that the dark colour of the English racehorse was due to the Arab dislike of light coloured horses. History puts it beyond doubt that the Arabs had no horses at the beginning of the Christian era, and that they obtained their famous breed from North Africa, and, so far from their disliking light coloured horses, they have a predilection, on religious grounds, for white or grey horses, as had the Germans, Greeks, and Romans. Bay and other dark coloured horses were well known in northern Africa and western Asia many centuries before the Arabs owned horses. The horse appears for the first time on Egyptian monuments about 1500 B.C., and is almost always painted brown, and those ridden by Libyans and depicted on pottery (at Daphne, B.c. 660-57o) are always painted dark. These horses were not imported into northern Africa from Asia; on the contrary, Solomon (tenth century B.c.) and his neighbours imported horses from Egypt which must have been of a superior race. These horses were obtained from the Libyan tribes (as none of the other peoples in that region possessed them), and from them also came those of southern Spain, the ancestors of the Andalusian and Pampas horses. The Libyan horses passed into Sicily and southern Italy, and in the games of Greece and in Roman times they were the fleetest known. The bay horse therefore not only belongs to Africa from the earliest times, but was then, as now, the swiftest. The Libyan horses show a greater tendency to stripes than do Asiatic horses, and the former often lack hock callosities, which are present and of large size in coarse Asiatic horses. The tail of the Libyan horse differs in structure, covering, and carriage from that of Asiatic horses; the hoofs are longer, and the neigh is different. Libyan horses were docile, and could be driven without bit, while the peoples who used AsioEuropean horses invented the bit. Prof. Ridgeway concludes that Equus caballus libicus is to be regarded as a distinct variety.

$$
\text { NO. I } 82 \mathrm{I} \text {, VOL. 70] }
$$

\section{THE ACTION OF WOOD ON A PHOTO. GRAPHIC PLATE IN THE DARK. ${ }^{1}$}

I T has been shown in former papers that many substances are capable of acting on a photographic plate in the dark and producing a picture of themselves. Further investigation shows that this property belongs probably to all woods, some, however, being much more active than others.

To obtain a picture the wood has to be in contact or at a little distance above the photographic plate, and has to remain there for times varying from half an hour to eighteen hours, and to be at a temperature not higher than $55^{\circ} \mathrm{C}$.

The wood of the conifers is very active, and gives pictures which are very definite. Fig. $I$ is a picture of a section of a branch of a Scotch fir, and shows well the rings of spring and autumn growth. It is remarkable that the former are very active, producing in this picture the dark rings, and so with the other pictures, the part which is active in the original is dark in the picture. The rings seen in the wood are very sharp and strongly pronounced in the picture. If the action exerted on the plate be owing to the presence of hydrogen peroxide, as has been previously suggested, no doubt it is produced by the resinous bodies

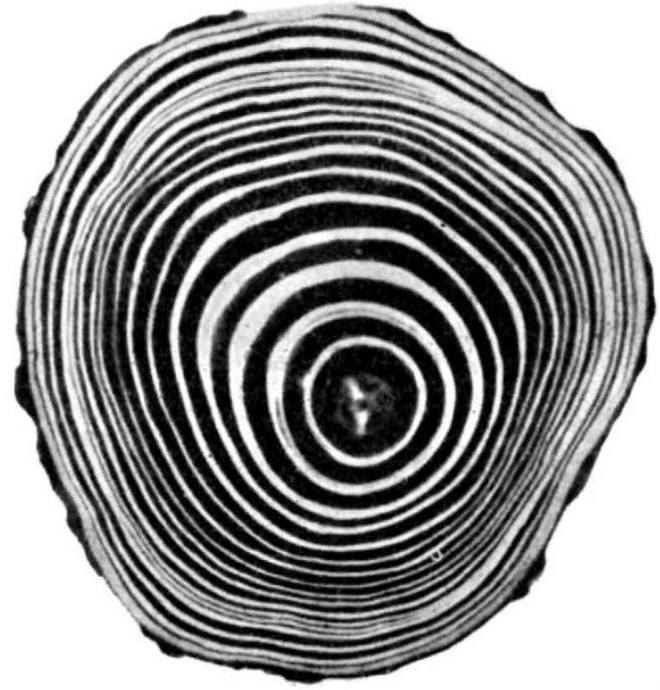

Fig. I.

present in the wood, but it is remarkable that there is no action from the dark autumn wood. Experiments described in the full paper show that resin exists in the dark rings, but apparently under such conditions that it cannot escape. Other members of the pine group have been experimented with and have been found to behave in the same way as the Scotch fir.

With the spruces the action on the plate is not so definite and well marked; the white wood is always active, but in some cases the dark rings are also active, and the pictures are not so sharp as with the firs. Larch wood gives a very interesting result, for the picture is the reverse of that of the Scotch fir, that is, the dark rings in the wood are the active rings and the light rings are inactive.

With regard to woods other than conifers, oak and beech are both active and give very good pictures, so also does acacia (Robinia), Spanish chestnut, and sycamore; on the other hand, ash, elm, horse chestnut, plane are comparatively but slightly active. In the full paper lists of woods are arranged according to their activity.

Many foreign woods are very active, but as the annual rings are often not well developed, the pictures they give are of a somewhat different character. The African black wood, rose wood, cocobola, and many others are very active. Several of the foreign woods have a ring of white wood which is quite inactive.

1 By Dr. William J. Russell, F.R.S. Read before the Royal Society, June 16. 
Knots in a wood generally, but not always, give a good picture. Some of the resin in immediate contact with the knot is in some cases but little active. The marked difference in properties of resins from different sources is described, and it is shown how difficult it is to remove it so that the wood shall be no longer active. Boards that have been exposed to the air for a long time, an oak box a hundred or more years old, rotten wood from the stump of a tree, and even bog wood have all been found to be still active.

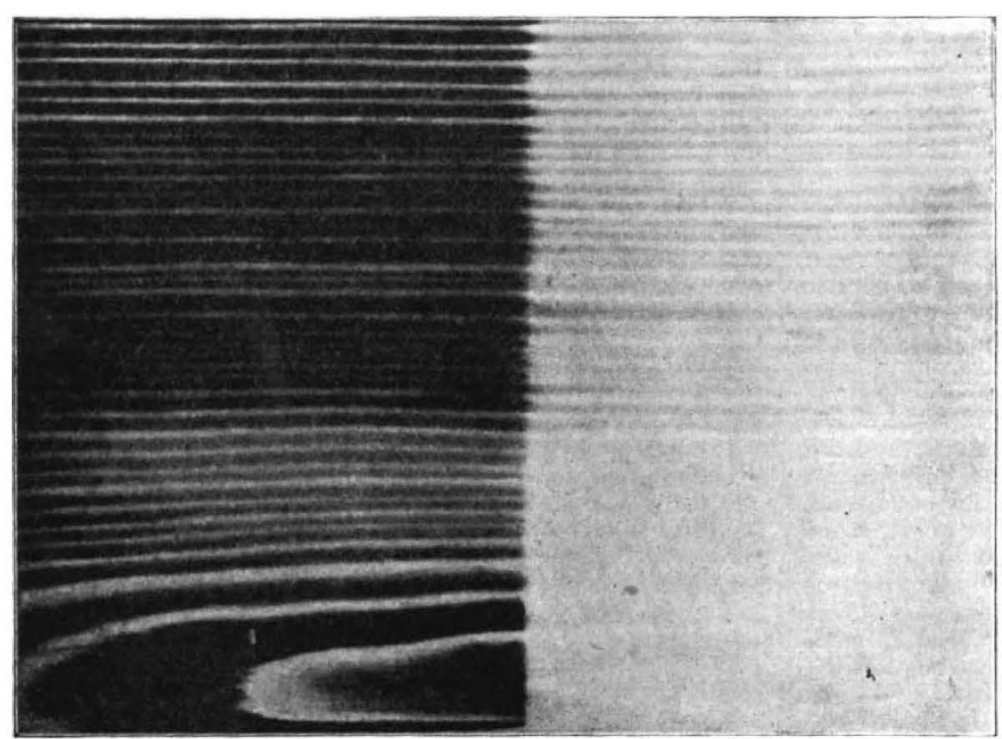

FIG. 2.

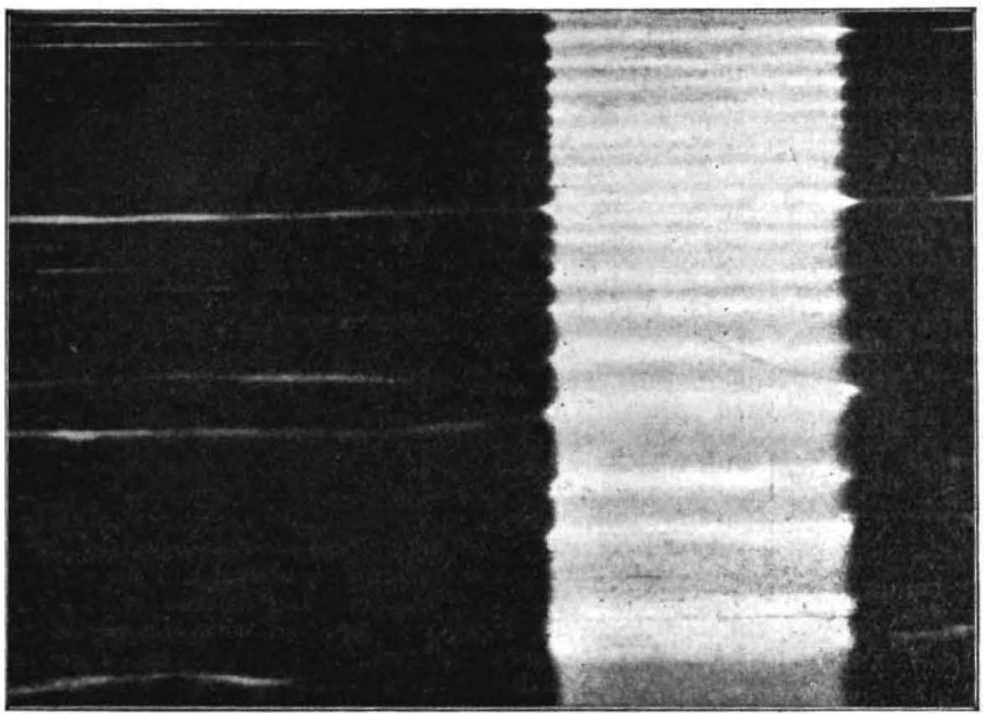

FIG. 3.

In addition to woods many different resins and allied bodies can, when used alone, be proved to be very active, some naturally much more so than others. Ordinary resins, Burgundy pitch, gum mastic, are very active, asphaltum, dragon's blood much less so, but true gums such as gum senegal and gum arabic are entirely without action on a photographic plate.

In certain cases the picture obtained on the plate does not resemble the markings which are visible on the wood. With some woods this more commonly occurs NO. I 82 I, VOL. 70] than with others. That this picture is persistent in the wood is shown by fresh sections giving the same result. The true bark of a wood is apparently quite without action on a photographic plate, so is the internal pith of a plant.

There is another and a very interesting action which occurs with wood; it is the great increase of activity which it exerts on a photographic plate after it has been exposed to a strong light. For instance, if a piece of deal be half covered by black paper or tin foil and be exposed for five to ten minutes to bright sunlight, and then put up in the usual way with a photographic plate, it will give a dark picture where the light has fallen on the wood and only a very faint picture of the part which has been covered. This is shown in Fig. 2. Even comparatively inactive woods such as $\mathrm{elm}$ and ivy after a short exposure to bright light give good and dark pictures. The action is not an indiscriminate darkening over the whole wood section, but an intensifying of the parts already active. This increase of activity by the action of light appears to occur with all woods. Artificial light, such as that from the electric arc, or from burning magnesium ribbon, act in the same way, so does even a faint light. A piece of wood put at a window for some hours will give a darker picture than a similar piece left in the middle of the room. This increase of power of a wood to produce a picture does not rapidly pass away. After twenty-four hours the action is visibly less, and decreases more rapidly at first than after some days, but it will be a fortnight or may be a month before the wood resumes its former condition. This action, like the former one, is entirely stopped by interposing the thinnest piece of glass or mica between the photographic plate and the active body. An inactive card painted with an alcoholic solution of resin acts in the same way, and turpentine which has been exposed to a bright light acts more strongly on a photographic plate than it does when it has not been so exposed. Again, old printing which is now nearly inactive becomes much more active after exposure to sunlight. Bodies other than those which may contain resin or allied substances are not affected in this way by light, for instance, flour, sugar, porcelain; metals are not rendered active by sunlight.

The next point was to ascertain which of the constituents of light was most active in producing these effects, and the first experiments were made by simply placing strips of different coloured glass on wood sections, exposing them to sunlight and afterwards putting them up with the photographic plate in the usual way. Pictures of the results are given in the paper. Red glass entirely prevented any increase in the activity of the wood, in fact, it acted in the same way as a band of black paper or tin foil would act, and a green glass acted much in the same way, but under a blue glass the activity of the wood was increased to much the same extent as under colourless glass or under no glass. Fig. 3 shows what happens when a red glass and a white glass are placed upon it and is exposed to sunlight. On the right of the figure there was no glass.

Further experiments were made by placing similar pieces of deal in light which had passed through different coloured solutions. Three double-cased bell jars were taken; one: 
was charged with a solution of potassium bichromate, another with copper ammonium sulphate solution, and the third with pure water, and all were exposed to sunlight for four hours. The deal in the red light gave only a faint picture, that in the blue light a dark picture, and that with the pure water was only a slightly darker picture. Resin, guaiacum, copal varnish, white oil paint and resin sized paper all acted in the same way and gave similar results.

The light from an arc lamp when passed through a red glass and allowed to fall on a wood section for one and a half hours produced no effect, but when the same light was passed through a blue glass and fell on a similar wood section for only one hour it produced a dark picture. With liquids this same increase of activity by the action of blue light is produced. Turpentine, which has been exposed to blue light, is more active than when in its ordinary condition.

\section{THE DENSITY OF NITROUS OXIDE. ${ }^{1}$}

[N the Proceedings, vol. 1xxii. p. $204,1897,{ }^{2}$ I have given particulars of weighings of nitrous oxide purified by two distinct methods. In the first procedure, solution in water was employed as a means of separating less soluble impurities, and the result was 3.6356 grams. In the second method a process of fractional distillation was employed. Gas drawn from the liquid so prepared gave 3.6362 . These numbers may be taken to represent the corrected weight of the gas which fills the globe at $0^{\circ} \mathrm{C}$. and at the pressure of the gauge $\left(\right.$ at $15^{\circ}$ ), and they correspond to 2.6276 for oxygen.

Inasmuch as nitrous oxide is heavier than the impurities likely to be contained in it, the second number was the more probable. But as I thought that the first method should also have given a good result, I contented myself with the mean of the two methods, viz. 3.6359 , from which I calculated that, referred to air (free from $\mathrm{H}_{2} \mathrm{O}$ and $\mathrm{CO}_{2}$ ) as unity, the density of nitrous oxide was $\mathrm{I} .5295 \mathrm{I}$.

The corresponding density found by $M$. Leduc is $\mathrm{r} .53 \mathrm{Or}$, appreciably higher than mine; and $M$. Leduc argues that the gas weighed by me must still have contained one or two thousandths of nitrogen. ${ }^{3}$ According to him the weight of the gas contained in my globe should be 3.6374 , or 1.5 milligrams above the mean of the two methods.

Wishing, if possible, to resolve the question thus raised, I have lately resumed these researches, purifying the nitrous oxide with the aid of liquid air kindly placed at my disposal by Sir J. Dewar, but I have not succeeded in raising the weight of my gas by more than a fraction of the discrepancy (I.5 milligrams). I have experimented with gas carefully prepared in the laboratory from nitrate of ammonia, but as most of the work related to material specially supplied in an iron bottle I will limit myself to it.

There are two ways in which the gas may be drawn from the supply. When the valve is upwards, the supply comes from the vapourous portion within the bottle, but when the valve is downwards, from the liquid portion. The latter is the more free from relatively volatile impurities, and accordingly gives the higher weight, and the difference between the two affords an indication of the amount of impurity present. After treatment with caustic alkali and sulphuric acid, the gas is conducted through a tap, which is closed when it is desired to make a vacuum over the frozen mass, and thence over phosphoric anhydride to the globe. For the details of apparatus, \&c., reference must be made to former papers.

The first experiment on July 13 was upon gas from the top of the bottle as supplied, and without treatment by liquid air, with the view of finding out the worst. The weight was 3.6015 , about 35 milligrams too light. The stock of material was then purified, much as in 1896 . For this purpose the bottle was cooled in ice and salt ${ }^{4}$ and allowed during about one hour to blow off half its contents, being subjected to violent shaking at frequent intervals. Subsequently three weighings were carried out with gas drawn from the bottom, but without treatment by liquid air. The

1 By Lord Rayleigh, O.M., F.R.S. Abridged from a paper received at the Royal Society on September I.

2 Or "Scientific Papers," vol. iv. p. 350.

(4) The lower the res Gaz." (Paris, 7898.) is this procedure likely to be.

NO. I 821 , vOL. 70] results stand:--July 18, 3.6368; July 20, 3.6360; July 25 , 36362 ; mean, 3.63633 .

Next followed experiments in which gas, still drawn from the bottom of the bottle, was further purified by condensation with liquid air. On one occasion (August 7 ) the condensed gas was allowed to liquefy, for which purpose the pressure must rise to not far short of atmospheric, and to blow off part of its contents :-August I, 3.6363 ; August $3,3.6367$; August $7,3.6366$; mean, 3.63653 .

The treatment with liquid air raised the weight by only o 2 milligram, but the improvement is probably real. That the stock in the bottle still contained appreciable impurity is indicated by a weighing on August ${ }_{13}$, in which without liquid air the gas was drawn from the top of the bottle. There appeared, August $13,3.6354$, about I milligram short of the proper weight.

It will be seen that the result without liquid air is almost identical with that found by the same method in 1806 , and that the further purification by mears of liquid air raises the weight only to 3.6365 . I find it difficult to believe that so purified the gas still contains appreciable quantities of nitrogen.

The corresponding weight of air being $2 \cdot 3772,{ }^{1}$ we find that, referred to air as unity, the density of nitrous oxide is $3.6365 / 2.3772=1.5297$. Again, if oxygen be taken as 16 , the density of nitrous oxide will be $3.6365 \times 16 / 2.6276=$ 22. 143 .

The excess above 22 is doubtless principally due to the departure of nitrous oxide from Boyle's law between atmospheric pressure and a condition of great rarefaction. I hope shortly to be in a position to apply the connection which will allow us to infer what is the ratio of molecular weights according to Avogadro's rule.

\section{UNIVERSITY AND EDUCATIONAL} INTELLIGENCE.

Mr. ERnest Shearer, Kirkwall, has been appointed lecturer on agriculture at the Pusa Imperial College, Bengal. This model agricultural college for all India, with a farm of 1300 acres attached, is one of the admirable developments resulting from the appointment two or three years ago of $\mathrm{Mr}$. James Mollison as Inspector-General of Agriculture in India. Mr. Alexander Sangster, Montrose, has been appointed junior assistant with the Aboukir Land Reclamation Co., near Alexandria, Egypt, and Mr. John C. Leslie assistant conservator of forests in southern Nigeria.

THE approach of the new sessions at polytechnics and similar institutes is heralded by the appearance of calendars and prospectuses, several of which have been received within the past few days. At the Birkbeck College, Chancery Lane, the session will commence on Monday, October 3 , when an inaugural address. will be delivered by Dr. J. E. Mackenzie on "The Influence of Pure Science on Progress." The class-rooms and laboratories of the college will afterwards be open to inspection, and demonstrations will be given. A course in science with practical work has been organised to give complete preparation in metallurgy and mining for those qualifying for the mining profession. It is satisfactory to know that within the last few years valuable reference libraries have been provided for the separate departments of science; these have been aided by grants from the County Council. His Majesty's Treasury recently presented to the college forty-nine volumes of the scientific results of the Challenger Expedition.

THREE prospectuses have been received from the Southwestern Polytechnic, referring respectively to the day college for men and women, day school for boys and girls, and evening classes. The principal of the polytechnic is Mr. S. Skinner. The courses at the day college are arranged to occupy three years. On entering the student has to state whether he wishes to be trained as a mechanical, civil, or electrical engineer, or as a consulting or industrial chemist. In any of these cases he will find mapped out for him a complete course of study, involving laboratory instruction, tutorial work, attendance at lectures, exercises in mathematics, geometrical, mechanical and architectural drawing, and instruction in the workshops.

1 Roy. Soc. Pruc., vo'. liii. p. 13 t, 1893 ; "Scientific Papers," vol p. 47 . 